\title{
Capítulo 9 \\ Una mirada a las pantallas: oferta cinematográfica en México antes $y$ después del TLC
}

\author{
María de la Luz Casas Pérez* \\ Instituto Tecnológico de Estudios Superiores de Monterrey, \\ Campus Cuernavaca
}

El cine es una importante industria a nivel internacional. En muchos países se le reconoce no solamente como una sólida fuente de ingresos, sino también debido a su potencial en la promoción de la cultura y de la identidad nacional.

En México el cine se ha descuidado durante décadas. El marco normativo que regula la actividad de la industria cinematográfica mexicana ha estado no solamente rezagado respecto de la dinámica de la producción cinematográfica en otros países, sino que ha dejado a la industria totalmente desprotegida respecto de la competencia internacional.

La presente investigación hace un recuento de la situación de la industria cinematográfica mexicana antes y después del TLC, de los cambios que la legislación cinematográfica facultó en su momento y de la forma en que éstos permitieron el ingreso aún más franco de la industria cinematográfica norteamericana a las pantallas mexicanas.

Cinema is as an important asset in most countries. Not only has it been recognized for its potential in revenues, but for the promotion of culture and national identity as well.

* Tiene licenciatura en Comunicación por la Universidad Iberoamericana, maestría en Comunicación por la Universidad de McGill en Montreal, Canadá y doctorado en Ciencia Política por la Universidad Nacional Autónoma de México. Es investigador nacional Nivel II, miembro de distintas asociaciones y autora de diversos artículos en revistas de comunicación y política. Su obra más reciente es "Políticas de Comunicación en América del Norte" Editorial Limusa, 2006. 
However, in Mexico cinema is not an essential industry. Differently from other countries, in Mexico the industry of cinema has always been dependent on the State not only for promotion but also for the assignment of Federal funding, which by the way has always being scarce. Legislation for the industry, not adequately updated for long, has left the industry on its own and at the hands of international competition. The situation of cinema theatres exhibition depicted in this paper before and after NAFTA, shows that the Mexican cinematographic industry may well be in the hands of the US interests for long.

El cine, es no solamente una industria del entretenimiento, sino también es una industria cultural. El cine constituye un vehículo para la expresión del arte, de la lengua, de la identidad y de la cultura de un pueblo.

El panorama multicolor de una nación puede expresarse de manera diversa a través de los matices que se difunden a través del cine. Por ello, resulta tan importante y tan significativa la oferta cultural que se transmite en las salas cinematográficas en un momento dado.

En muchos países, el cine es considerado una industria prioritaria, y en la mayoría de los casos el Estado no ha renunciado a su rectoría, antes bien la ha fortalecido ${ }^{1}$.

El cine forma parte de nuestra identidad, nuestras costumbres, nuestras formas de ser y de sentir. Por eso, el cine refleja el rostro de nuestra sociedad, y resulta importante saber cómo es que ha ido cambiando ese rostro a lo largo de los últimos años.

Hace algunos años, a muchos de nosotros nos preocupó cómo cambiaría el rostro de nuestro país a consecuencia de la entrada en vigor del Tratado de Libre Comercio de América del Norte (TLC). ¿Se transformaría el consumo? ¿Terminaríamos consumiendo muchos más productos estadounidenses de los que ya consumíamos? ¿Habría posibilidad de que nuestra oferta mediática llegara a las pantallas y a las salas cinematográficas en Estados Unidos y Canadá?

\footnotetext{
${ }^{1}$ Particularmente en países como Estados Unidos y Canadá que son nuestros socios comerciales en el TLC el cine constituye una industria prioritaria, financiada directamente para la producción de materiales propios, como en el caso del Nacional Film Board of Canada, o indirectamente a través de la protección al ingreso de materiales extranjeros como en el caso del Departamento de Estado de los Estados Unidos. De hecho, la Casa Blanca reconoce en el cine una de sus primeras fuentes de divisas después de la industria del automóvil y la de las armas. En otros países, como en Francia, España, Argentina y Brasil la producción cinematográfica nacional recibe incentivos políticos y fiscales.
} 
El presente trabajo pretende abordar precisamente esta pregunta acudiendo a los datos duros, es decir al conteo de la oferta cinematográfica tal y como fue reportada por las carteleras mexicanas en dos momentos específicos: uno, en 1994 al momento de la entrada en vigor del TLC a fin de observar cuál era la situación en esos momentos en términos de exhibición, y otro en el año 2004, es decir a diez años de la entrada en vigor de dicho tratado. Sin embargo, este trabajo no solamente aborda la cuestión del número de películas exhibidas en cada período, sino que también analiza los cambios en la legislación que se desarrollaron a consecuencia del contexto específico de competencia a la que se enfrentaba nuestro país en el sector cinematográfico.

Como sabemos, diversos sectores de la economía y no solamente el cinematográfico, fueron preparados para el ingreso de México al TLC, pero la industria del cine en particular se encontraba en una situación particularmente difícil. El cine había demostrado ser no solamente una industria productiva, sino también muy importante en la conformación de una identidad nacional fuerte y generosa.

Durante 1950, México llegó a producir 122 películas por año, pero los años prolíficos llegaron a su fin, no obstante que durante la década de los setenta se habían hecho esfuerzos para promover la producción nacional. Para 1998, el cine mexicano tocaba fondo ${ }^{2}$.

La industria cinematográfica mexicana adolece de muchos problemas, pero el principal de ellos es la falta de fuentes de financiamiento, ya que ha demostrado ampliamente contar con talento y creatividad a la altura de cualquier otro país. Salvado el problema del financiamiento el siguiente problema es la distribución de las películas. Acostumbrados a la avalancha de productos cinematográficos, principalmente norteamericanos, los canales de distribución privilegian la oferta cinematográfica norteamericana ya que es la que cuenta con mayores facilidades para la promoción. Compromisos adicionales de las salas cinematográficas con los distribuidores permiten privilegiar la exhibición de películas norteamericanas por encima de las películas nacionales.

${ }^{2}$ Sólo se produjeron 12 películas de las cuales se exhibieron 6. Para el año 2000 se logran filmar 28 y 4 quedan en proceso de producción. Ver declaraciones de Víctor Hugo Rascón Banda en ocasión de la presentación del reglamento de la Ley Federal de Cinematografía el 30 de marzo del 2001. Disponible en: http://www.cnca.gob.mx/cnca/nuevo/2001/diarias/mar/300301/leyfcine.html 
Como veremos más adelante, el marco jurídico mexicano sobre el cual opera la industria no favorece a la exhibición, ni les otorga beneficios o protección a los productores. Así el contexto de la exhibición se encuentra íntimamente relacionado con las condiciones de promoción, financiamiento, lo cual condiciona ampliamente las condiciones de participación de los involucrados y merma los esfuerzos de productores, guionistas, directores y otros actores importantes del sector para producir una oferta cultural cinematográfica netamente mexicana.

\section{LA OFERTA CULTURAL CINEMATOGRÁFICA}

El problema del consumo cinematográfico es complejo. Como hemos visto, se trata de un fenómeno en el cual intervienen distintos factores que responden desde luego a condiciones históricas particulares (Sánchez, citado en García, 2004).

Es cierto que el público mexicano puede haber desarrollado un cierto "gusto por el cine extranjero", pero también es cierto que sectores específicos de la propia industria, como los distribuidores, han operado, muchas veces en contra de la propia producción nacional favoreciendo al consumo de productos extranjeros a fin de garantizar sus ingresos en taquilla.

El fenómeno no es nuevo, sin embargo, sí responde a las condiciones de competencia internacional de los mercados globales.

Mientras la economía mexicana estuvo cerrada, la producción nacional tenía su exhibición prácticamente garantizada en las carteleras cinematográficas mexicanas, pero a consecuencia de la entrada en México del TLC las condiciones de la competencia cambiaron, y tanto distribuidores como exhibidores optaron por el responder a la demanda en volumen.

La legislación no ayudaba mucho tampoco. Las primeras normas jurídicas que normaban la industria cinematográfica se habían producido en el contexto del proteccionismo estatal y no habían vuelto a revisarse porque respondían muy bien a los intereses tanto del gobierno como de la industria. Sin embargo, en el momento en que nuevos actores internacionales entraron en escena se hizo necesaria una revisión profunda de la norma jurídica. No obstante esa revisión llegó demasiado tarde, dejando en la indefensión absoluta a una industria que debió de haber sido protegida desde un principio como forma de expresión nacional. 
Si bien el cinematógrafo fue conocido en nuestro país desde la época del Presidente Porfirio Díaz, y existen documentos cinematográficos que consignan la presencia del cine en México y que dan cuenta de los principales acontecimientos de la época desde la decena trágica y revolución, no es sino hasta la década de los ańos cuarenta que el cine comercial recibe su primer auge.

En parte, el impulso recibido por la industria cinematográfica mexicana se debió al interés de los Estados Unidos por promover los valores de la doctrina Monroe frente a las posibilidades de la expansión nazi en Alemania.

Es precisamente hacia finales de los años treinta que los productores mexicanos reciben financiamiento para comprar equipos de cine, así como recibir asistencia técnica directamente de Hollywood para producir películas nacionales con la consigna de elevar el valor patriótico del país y su vinculación con el resto de las naciones americanas. (Ortiz Garza, 1989).

Este hecho en particular favoreció no solamente la introducción de equipo cinematográfico a nuestro país, sino también un cierto entrenamiento técnico en el know how de la producción y distribución de películas.

No obstante, y pese a la buena cantidad de producciones mexicanas que se desarrollarían hacia finales de los años treinta y principios de los años cuarenta, no sería sino hasta 1949 que se gestaría un marco regulatorio específico para esta industria ${ }^{3}$.

Esa ley establecía, por ejemplo las siguientes consignas, mismas que se transcriben a la letra:

Durante los sexenios de Luis Echeverría Álvarez y de José López Portillo la cinematografía mexicana recibiría cierto impulso sobre todo a través de financiamientos gubernamentales que, salvo escasas excepciones no produciría cine de buena calidad.

La consigna era producir cine, y no necesariamente buen cine. En muchos casos el financiamiento gubernamental al cine nacional estuvo condicionado a la producción de películas con contenidos ligeros y de baja calidad. No obstante, se llegaron a realizar algunas producciones de cine independiente que no vieron la luz sino hasta décadas posteriores.

${ }^{3}$ La primera Ley de la Industria Cinematográfica fue publicada en el Diario Oficial de la Federación el 31 de diciembre de 1949, durante la Presidencia de Miguel Alemán.

Una mirada a las pantallas: oferta cinematográfica en México antes y después del TLC 221 
Durante todos estos años, el énfasis de la regulación de la industria se centraría en la censura de los contenidos, muy al estilo de los funcionarios encargados en cada período.

La apertura política de finales de los años ochenta se reflejaría en la industria. Productores, guionistas y directores comenzaron a conquistar espacios con contenidos cada vez más ambiciosos escapando a la censura, sin embargo, el problema no era la falta de talentos o ideas para la producción, sino los financiamientos y la distribución.

Ante la retirada del Estado con fondos estatales para la producción de películas nacionales, los talentos mexicanos tuvieron que emigrar a otras latitudes en busca de oportunidades, ya sea para la actuación o para la producción de sus películas. La ley de 1949 y el reglamento de $1973^{4}$ ya no eran suficientes para promover a la industria, por lo tanto para 1992 era claro que se requería una nueva legislación. Durante el sexenio de Carlos Salinas de Gortari, la legislación recibió modificaciones importantes. México se preparaba para la apertura.

La entrada de México al TLC abriría por tanto oportunidades, pero también problemáticas. Si bien el cine podría contar con mayores facilidades para el financiamiento tanto en producciones nacionales como en coproducciones, los realizadores también se enfrentaban a la competencia abierta y desmedida del cine extranjero, especialmente Hollywoodense.

Por otra parte, y en consonancia con la venta de paraestatales y el adelgazamiento del Estado, en 1993 el gobierno mexicano vendía un paquete de medios entre los que se encontraba la compañía Operadora de Teatros, S.A. Esta oportunidad resultó de oro para inversionistas mexicanos y extranjeros que vieron en ello la ocasión para comprar salas cinematográficas bien ubicadas y convertirlas en nuevos complejos cinematográficos de primer nivel ${ }^{5}$.

La Ley Federal de Cinematografía promulgada en diciembre de 1992 durante el sexenio del Presidente Carlos Salinas de Gortari ya comenzaba a

${ }^{4}$ Este reglamento es el mismo que aplica la Dirección General de Radio, Televisión y Cinematografía de la Secretaría de Gobernación, relativo a los contenidos de la radio y la televisión. Dicho reglamento fue publicado el 4 de abril de 1973 http://www.ordenjuridico. gob.mx/Federal/Combo/Reglamentos/R-87.pdf,,

${ }^{5}$ Hay que mencionar que para esas fechas las salas cinematográficas de las principales ciudades de la República mexicana se encontraban en un estado realmente deplorable, y que los consumidores de películas preferían en todo caso recurrir a la renta de videocasetes para tener la ocasión de ver los principales éxitos cinematográficos. 
acoplarse a los lineamientos expresados por el TLC que estaba en negociación en esos momentos ${ }^{6}$.

Así por ejemplo, según el Artículo $7^{\circ}$ de la ley de 1992, se consideran películas de producción nacional las que cubran los siguientes requisitos: haber sido realizadas por personas físicas o morales mexicanas ó haberse realizado en el marco de los acuerdos internacionales o los convenios de coproducción suscritos por el gobierno mexicano con otros países u organismos internacionales ${ }^{7}$.

El Artículo $8^{\circ}$ de esa misma ley indica que las películas serán exhibidas al público en su versión original y, en todo caso subtituladas al español en los términos que establezca el reglamento ${ }^{8}$. Las clasificadas para público infantil y los documentales educativos, podrán exhibirse doblados al español.

Hay que mencionar que las multas y sanciones a las que hace referencia esta ley, no varían respecto de las establecidas en 1949, siendo la multa establecida por el Artículo $12^{\circ}$ de 400 a 4,000 salarios mínimos?.

La Ley de 1992 en su párrafo de Transitorios, establece los siguientes porcentajes de exhibición de producciones nacionales:

I. A partir de la entrada en vigor de la presente ley y hasta el 31 de diciembre de 1993 - el 30\%

II. Del 1 de enero al 31 de diciembre de 1994 - el 25\%

III. Del 1 de enero al 31 de diciembre de 1995 - el 20\%

IV. Del 1 de enero al 31 de diciembre de 1996 - el 15\% y

V. Del 1 de enero al 31 de diciembre de 1997 - el 10\%

Es importante hacer mención de que la liberalización paulatina del sector pretendía darle a esta industria el suficiente tiempo para incentivar la producción nacional, pero sin beneficiarla con un tratamiento especial sino lanzarla a la libre competencia de la oferta cinematográfica en concordancia con las negociaciones del TLC hasta ese momento.

\footnotetext{
${ }^{6}$ Esta ley fue publicada en respuesta a la inquietud manifiesta de diversos sectores de la industria, cuya preocupación era la de actualizar las normas jurídicas existentes desde 1949; sin embargo, como la ley de 1992 tampoco respondió a las expectativas de la comunidad de productores y realizadores de la industria cinematográfica, a partir de 1995 se llevaron a cabo foros de consulta que permitieran una nueva actualización de la ley.

${ }^{7}$ Ley Federal de Cinematografía Diario Oficial de la Federación 23 de diciembre de 1992.

${ }^{8}$ Se refiere al reglamento de 1973 .

${ }^{9}$ Sólo en caso de reincidencia se considerará doblar el monto correspondiente a la sanción.
} 
Cuadro I

Número de producciones cinematográficas exhibidas durante el año de 1994

\begin{tabular}{|c|c|c|c|c|}
\hline PAÍs & NÚMERo & $\%$ DEL & NÚMERo & \% DEL \\
\hline PRODUCTOR & $\mathrm{DE}$ & NÚMERO & DE & NÚMERO DE \\
\hline DE LA CINTA & PELÍCULAS & DE CINTAS & EXHIBICIONES & EXHIBICIONES \\
\hline$\overline{\text { EUA }}$ & 128 & 61.5 & 9873 & 62.2 \\
\hline México & 36 & 17.3 & 2858 & 18.0 \\
\hline Italia & 7 & 3.3 & 433 & 2.7 \\
\hline No identificado & 6 & 2.8 & 782 & 4.9 \\
\hline Francia/Inglaterra & 5 & 2.4 & 210 & 1.3 \\
\hline Alemania & 4 & 1.9 & 86 & 0.5 \\
\hline Japón & 4 & 1.9 & 56 & 0.3 \\
\hline España & 3 & 1.4 & 279 & 1.7 \\
\hline España/Portugal/Francia & 3 & 1.4 & 153 & 0.9 \\
\hline Argentina & 2 & 0.9 & 56 & 0.3 \\
\hline Nueva Zelanda & 2 & 0.9 & 332 & 2.0 \\
\hline Hong Kong & 2 & 0.9 & 303 & 1.9 \\
\hline Inglaterra & 1 & 0.4 & 119 & 0.7 \\
\hline EUA/Inglaterra & 1 & 0.4 & 128 & 0.8 \\
\hline Holanda & 1 & 0.4 & 93 & 0.5 \\
\hline Suiza/Bélgica/España & 1 & 0.4 & 10 & 0.06 \\
\hline Cuba/España/México & 1 & 0.4 & 36 & 0.2 \\
\hline España/Portugal/Francia & 1 & 0.4 & 57 & 0.3 \\
\hline$\frac{1}{\text { Total }}$ & 208 & 99.9 & 15864 & 99.9 \\
\hline
\end{tabular}

Fuente: $\mathrm{CINCO}^{10}$

\begin{tabular}{lrr} 
Número de producciones & 196 & $94.23 \%$ \\
Número de co-producciones & 12 & $5.76 \%$ \\
\hline Total & 208 & $99.99 \%$
\end{tabular}

Como se observar en el cuadro el número de producciones nacionales destaca notablemente la presencia de Estados Unidos, mientras que nuestro segundo socio en el TLC todavía no aparece. Comienzan a aparecer algunas producciones y co-producciones extranjeras. No obstante el número de cintas y de exhibiciones no destaca todavía. Lo que sí es un hecho es que la industria

${ }^{10}$ Datos proporcionados por el Centro de Investigación en Comunicación e Información (CINCO) del Tecnológico de Monterrey, Campus Monterrey. La información fue obtenida con base en una muestra representativa obtenida de manera aleatoria de 10 de las 52 semanas del año durante el año de 1994 y publicada en la cartelera cinematográfica de la Ciudad de México. La autora desea agradecer al Maestro Francisco Javier Martínez Garza y al Doctor José Carlos Lozano el haberle facilitado estos datos. 
no cumple con los requisitos de ley previstos para el año 1994 en el cual debió de haber habido al menos un $25 \%$ de producción nacional en el tiempo de pantalla, y apenas se llegó a un $18.01 \%$.

Para 1999 el gremio de los productores, directores, realizadores y cineastas se quejaban amargamente de no tener los apoyos suficientes para compensar con producciones nacionales la avalancha de la oferta cinematográfica extranjera, primordialmente la norteamericana, mientras que por otro lado los distribuidores y exhibidores argumentaban que se debía dejar a la libre competencia del mercado y al gusto de los consumidores lo que finalmente se expusiera en las pantallas cinematográficas ${ }^{11}$. Ante la novedad de las salas renovadas y de las películas americanas que se exhibían casi al mismo tiempo que en los Estados Unidos los consumidores del cine mexicano se habían convertido en el nuevo gran negocio. La industria daba síntomas de no estar a la altura de la competencia internacional y todos los actores clamaban por un nuevo orden regulativo. Ante la presión de la industria, la reglamentación es nuevamente modificada en $1999^{12}$.

$\mathrm{Al}$ inicio del nuevo milenio, productores, distribuidores y exhibidores estaban ya operando la industria con nuevas bases reglamentarias.

La Ley de la Industria Cinematográfica de 1999 registró los siguientes cambios significativos:

Por principio de cuentas, en el Artículo $13^{\circ}$ del Capítulo II de la Producción Cinematográfica, se establece la figura de productor como la persona física o moral que "tiene la iniciativa, la coordinación y la responsabilidad de la realización de una película cinematográfica".

${ }^{11}$ Un decreto que prometía reformar dicha ley fue publicado el 5 de enero de 1999 y obligaba al Ejecutivo Federal en su artículo $3^{\circ}$ transitorio, a publicar el reglamento respectivo en un plazo no mayor de 90 días, lo cual nunca sucedió. Ya durante el gobierno del Presidente Vicente Fox, el Consejo Nacional para la Cultura y las Artes CONACULTA, se hicieron ajustes para incluir algunos aspectos relativos al papel del Estado en la promoción del cine nacional. Esto culminó con la publicación del reglamento a la Ley Federal de Cinematografía, en abril de 2001, que establecía la creación del Fondo de Inversión y Estímulos al Cine, conocido como FIDECINE. Se esperaba que esta medida le diera un buen impulso al cine nacional; si es que lo hubo sin embargo, como veremos más adelante, los datos de la oferta cinematográfica posterior a 2001 parecen no reflejar adecuadamente dicho impulso.

${ }^{12}$ La Ley de Cinematografía vigente fue publicada en el Diario Oficial de la Federación el 29 de diciembre de 1992 y modificada el 5 de enero de 1999. Ver documento oficial en: http://www.ordenjuridico.gob.mx/Federal/PL/CU/Leyes/29121992(1).pdf

Una mirada a las pantallas: oferta cinematográfica en México antes y después del TLC $\bullet 225$ 
El Artículo $14^{\circ}$ establece que la producción nacional constituye una actividad de interés social, "sin menoscabo de su carácter industrial y comercial" por expresar la cultura mexicana y contribuir a fortalecer los vínculos de identidad nacional entre los diferentes grupos que la conforman. Por tanto, "el Estado fomentará su desarrollo para cumplir la función de fortalecer la composición pluricultural de la nación mexicana mediante los apoyos e incentivos que la ley señale”.

Por su parte, el Artículo $15^{\circ}$ consigna como co-producción a "aquella película cinematográfica en cuya producción intervengan dos o más personas físicas o morales". Se considera co-producción internacional la producción que se realice "entre dos o más personas extranjeras con la intervención de una o varias personas mexicanas bajo los acuerdos o convenios internacionales que en esta materia estén suscritos por México".

El Artículo $18^{\circ}$ de la misma ley, por primera vez consigna la posibilidad de la distribución y exhibición de películas por otra vía que no sea exclusivamente la de la exhibición en sala cinematográfica, permitiendo por ejemplo la transmisión y distribución en sistema abierto o cerrado, por hilo o sin hilo ${ }^{13}$, electrónico o digital, así como su comercialización por videograma, disco compacto o láser, así como cualquier otro sistema para su duplicación, venta o alquiler, lo mismo que para su acceso vía navegación por el ciberespacio, realidad virtual o cualquier otro medio conocido o por conocer ${ }^{14}$.

El Artículo $19^{\circ}$ por su parte ya establece la prescripción de mantener exclusivamente un $10 \%$ del tiempo de pantalla dedicado a la exhibición de producción cinematográfica nacional, mientras que el Artículo $23^{\circ}$ indica que con el fin de observar la identidad lingüística nacional, el doblaje de películas extranjeras se realizará en la República mexicana, con personal y actores mexicanos o extranjeros residentes en el país, salvo las disposiciones contenidas en los tratados internacionales ${ }^{15}$.

La clasificación de películas se llevará a cabo a través de la Dirección General de Radio, Televisión y Cinematografía en los términos de la reglamentación vigente en materia de clasificación de contenidos.

\footnotetext{
${ }^{13}$ Léase a través de sistema de cable o vía satélite.

${ }^{14}$ Normalmente las legislaciones dejan estos huecos abiertos en la legislación, lo cual permite incluir a cualquier otro dispositivo tecnológico de creación posterior a la promulgación del instrumento.

${ }^{15}$ Esto deja la puerta abierta por ejemplo a que las grandes trasnacionales productoras de películas tomen esta prerrogativa para producir sus películas en DVD incluyendo doblajes al español realizados fuera de las fronteras mexicanas.
} 
Por su parte, el Capítulo VII del Fomento a la Industria Cinematográfica, en sus Artículos $31^{\circ}$ a $38^{\circ}$ establece la creación de un fideicomiso para el fomento a la producción cinematográfica nacional integrada con incentivos que determinará en su caso el Ejecutivo Nacional ${ }^{16}$.

El Artículo 45 incrementó de 500 a 5,000 veces el salario mínimo el monto de las sanciones a las que se hará acreedora cualquier violación a la presente ley ${ }^{17}$.

Las críticas a la aprobación de esta ley no se hicieron esperar, ya que el proceso había incluido la participación de distintos actores de la industria en audiencias públicas que se prolongaron durante varios meses ${ }^{18}$, después de transcurridos los cuales, de todas maneras el Estado pactó con los exhibidores.

Esta vez el debate se había centrado no en la regulación, la censura y el control de los contenidos, como en los circuitos de distribución y exhibición de las películas mexicanas. Los exhibidores argumentaron que el público mexicano no deseaba pagar un incremento al boleto en taquilla, por pequeño que este fuera, y defendió el derecho del público asistente a las salas cinematográficas de elegir sus películas independientemente de su nacionalidad ${ }^{19}$. El proyecto de ley fue

${ }^{16}$ Originalmente la iniciativa de ley que habían manejado diversos grupos (incluyendo cineastas, productores, realizadores, así como legisladores del grupo parlamentario de la oposición) incluían la propuesta de destinar \$ 1.00 (un peso) del boleto vendido en taquilla, a este fondo de financiamiento para el cine nacional. La propuesta original fue desechada.

${ }^{17}$ Esta versión de la Ley Federal de Cinematografía vigente fue publicada en el Diario Oficial de la Federación el 5 de enero de 1999. Ver documento oficial en: http://www. ordenjuridico.gob.mx/Federal/PL/CU/Leyes/29121992(1).pdf

${ }^{18}$ Una fracción parlamentaria de la oposición intentó promover una nueva iniciativa de ley en la materia. Exhibidores y artistas se enfrascaron en una discusión relativa a la industria cinematográfica, y en la cual un grupo de legisladores de distintos partidos políticos presentaron un proyecto de ley que contemplaba el hecho de que todas las películas extranjeras exhibidas en México, tanto en cine como en televisión, deberían ser subtituladas, salvo las infantiles y de dibujos animados. La iniciativa también señalaba que todas las salas cinematográficas deberían exhibir películas mexicanas hasta alcanzar un $30 \%$ del total de sus funciones por pantalla. Para crear un Fondo de Inversión y Estímulos al Cine, el proyecto de ley establecía la aportación de un $5 \%$ del total de los ingresos en taquilla de las salas cinematográficas. Lo anterior con el propósito de promover el consumo de cine nacional en nuestro país para fomentar el fondo de producción nacional al que ya se hizo referencia anteriormente.

${ }^{19}$ A fin de frenar la iniciativa, la Cámara Nacional de la Industria Cinematográfica aplicó una encuesta a asistentes a las salas de cine en la que se preguntaba si se estaba de acuerdo con estas medidas. Los resultados fueron desalentadores hacia la propuesta de ley. Ver. Adriana Garay (1998). “Seguirán ley del amparo”. En: Reforma Nov. 5 Pág. 1, consultado el 18 de agosto del 2005 en: http://0-proquest.umi.com.millenium.itesm.mx/pqdlink?in

Una mirada a las pantallas: oferta cinematográfica en México antes y después del TLC $\bullet 227$ 
aprobado en 1998, pero con modificaciones a los puntos más polémicos de la propuesta original, como la exhibición obligatoria de películas mexicanas, el porcentaje por cada boleto vendido que iría a un fondo de estímulos al cine nacional y el doblaje.

Una de las modificaciones a la propuesta original provino seguramente de la presión de las compañías exhibidoras que, para ese entonces, ya estaban ingresando a México y que estaban constituidas con capital extranjero, predominantemente norteamericano.

Como vimos anteriormente en el texto de la ley vigente, según las reformas aprobadas, las salas cinematográficas deberán dedicar únicamente un $10 \%$ de su exhibición al cine mexicano, en lugar de $30 \%$ como lo planteaba la iniciativa original $^{20}$. Otra de las cuestiones que tampoco se modificó fue la cuestión del idioma, ya que los diputados tampoco hicieron cambios en cuanto a la legislación referente al doblaje, por lo que se mantiene la disposición de que se hará en México, con personal mexicano o extranjeros residentes en el país, a fin de conservar la identidad lingüística nacional. Un dato importante a considerar en este aspecto es la forma en que los exhibidores lograron torcer la ley de manera que las películas dobladas al español o con subtítulos fuesen consideradas como parte del porcentaje de oferta de cine nacional.

Ahora bien, Ley Federal de Cinematografía vigente no especifica los procedimientos específicos ni los criterios que habrán tomarse en cuenta para declarar producciones nacionales a los productos cinematográficos nacionales, sobre todo tomando en consideración que se considera co-producción a aquella producción cinematográfica en donde intervenga equipo o personal extranjero. Esta consigna resulta doblemente absurda si tomamos en consideración que la tecnología utilizada, los equipos de producción, así como el personal que trabaja en locaciones fuera del territorio nacional frecuentemente son de origen local, es decir, extranjero.

Tomando estos detalles en consideración, y haciendo un análisis comparativo respecto de los datos obtenidos durante el año 1994 el cuadro muestra que en el ańo 2004, a diez años de la entrada en vigor del TLC, el número total de cintas exhibidas es menor que el registrado en 1994, la cantidad de produc-

$\mathrm{dex}=9 \& \mathrm{did}=35742500 \&$ SrchMode $=1 \&$ sid $=1 \& \mathrm{Fmt}=3 \& \mathrm{VInst}=$ PROD $\&$ VType $=$ PQD $\& \mathrm{R}$ $\mathrm{QT}=309 \& \mathrm{VName}=\mathrm{PQD} \& \mathrm{TS}=1124392240 \&$ clientId=23693

${ }^{20}$ Una vez registradas las películas deberán exhibirse en un plazo que no sobrepase a los seis meses. 
ciones sigue estando concentrado en los Estados Unidos, con incremento del $12 \%$ con respecto a los porcentajes de ese año. El número de exhibiciones se incrementa con respecto a 1994 en un $46.43 \%$ lo cual habla de un fenómeno de concentración de la exhibición sobre una oferta más reducida, siendo el porcentaje de películas norteamericanas el lugar en donde se observa la mayor parte de las cintas y de las exhibiciones proyectadas (Por primera vez aparece Canadá en la lista de países que exportaron sus producciones cinematográficas a México, aunque el porcentaje es todavía muy pequeño).

\section{CuAdro 2}

Número de producciones cinematográficas exhibidas durante el año de 2004

\begin{tabular}{|c|c|c|c|c|}
\hline $\begin{array}{l}\text { PAÍ́s PRODUCTOR } \\
\text { DE LA CINTA }\end{array}$ & $\begin{array}{l}\text { NÚMERO } \\
\text { DE PELÍ́CULAS }\end{array}$ & $\begin{array}{l}\% \text { DEL NÚMERO } \\
\text { DE CINTAS }\end{array}$ & $\begin{array}{l}\text { NÚMERO DE } \\
\text { EXHIBICIONES }\end{array}$ & $\begin{array}{l}\text { \% DEL NÚMERO } \\
\text { DE EXHIBICIONES }\end{array}$ \\
\hline$\overline{\text { EUA }}$ & 116 & 74.3 & 26900 & 90.8 \\
\hline México & 8 & 5.1 & 1682 & 5.6 \\
\hline España & 7 & 4.4 & 387 & 1.3 \\
\hline Inglaterra & 4 & 2.5 & 79 & 0.2 \\
\hline Francia & 16 & 10.2 & 454 & 1.5 \\
\hline Canadá & 5 & 3.2 & 114 & 0.3 \\
\hline Total & 156 & 99.9 & 29616 & 98.9 \\
\hline
\end{tabular}

Fuente: $\mathrm{CINCO}^{21}$

Era claro entonces el desbordamiento en la oferta cinematográfica norteamericana con respecto de la oferta nacional, e incluso por sobre las otras opciones de cine extranjero. Los cineastas mexicanos luchaban por mantener su producción a flote.

Al no encontrar un apoyo directo por parte del Estado y no poder depender exclusivamente del fondo para el financiamiento a la producción nacional, (Fondo de Inversión y Estímulos al Cine), productores, guionistas, directores y realizadores han tenido que recurrir a socios y co-productores extranjeros. Lo cual indica que ciertamente, la única forma en que la cinematografía nacional ha logrado incrementar su producción ha sido a través de co-producciones.

${ }^{21}$ La metodología nuevamente se repitió y, de la misma manera se sacaron los datos con base en una muestra representativa obtenida de manera aleatoria de 10 las 52 semanas del año durante 2004 y publicada en la cartelera cinematográfica de la Ciudad de México. Tabla elaborada con base en los datos proporcionados por el Centro de Investigación en Comunicación e Información del Tecnológico de Monterrey, Campus Monterrey. 
La siguiente tabla muestra el monto de las co-producciones exhibidas durante el 2004 en salas cinematográficas mexicanas.

\begin{tabular}{lrr} 
Número de producciones & 156 & $66.10 \%$ \\
Número de co-producciones & 80 & $33.89 \%$ \\
\hline Total & 236 & $99.99 \%$
\end{tabular}

Así comparativamente, tanto el número de producciones de un solo país como el número de co-producciones varió con relación a 1994. Las producciones de un solo país disminuyeron en un $28.1 \%$ con respecto a 1994 , mientras que las co-producciones se incrementaron en un $28.1 \%{ }^{22}$.

Lo que sabemos es que del número total de exhibiciones durante el año 2004 el 90.8\% fueron de origen norteamericano, mientras que apenas el 5.6\% fueron de origen mexicano, lo cual evidentemente no permitiría cumplir con los requisitos de ley.

Un dato que no tenemos es cuántas cintas exhibidas en 2004 (independientemente de su origen) fueron exhibidas en español para así cubrir la cuota del $10 \%$ del total de tiempo de exhibición en salas cinematográficas consideradas como producción nacional pero, dado que seguramente de este alto porcentaje de exhibición habrá habido películas infantiles, podemos suponer que el porcentaje se cubrió sin ningún problema, de otra suerte los exhibidores se hubiesen hecho acreedores a la sanción correspondiente, dañando así su imagen ${ }^{23}$.

Es importante mencionar, que esta tendencia con referencia al origen norteamericano de las películas se mantuvo durante el año 2005. Así, en una investigación realizada nuevamente por el Centro de Investigación en Información y Comunicación (CINCO) del Tecnológico de Monterrey, se comprobó que el 47\% de las películas exhibidas en México durante el año 2005 fue de origen norteamericano, y que apenas el $9 \%$ fue de origen mexicano. Nuevamente, el resto de los países que ofertaron películas tuvieron muy baja participación.

Por otra parte, en 2005 la exhibición de películas consideradas coproducciones con Estados Unidos fue del 86\%. Este porcentaje registró un incremento respecto del año anterior, seguramente debido a la existencia de financiamientos

\footnotetext{
${ }^{22}$ Estos datos coinciden con los hallazgos de otros investigadores que indican que mientras que México había producido 747 películas en la década anterior a la entrada en vigor del TLC, a partir de 1994 redujo su producción a 212 largometrajes. (Ugalde, 2004, en García Canclini, 2004, pp. 202 y 203).

${ }^{23}$ Lo cual evidentemente tampoco habría sido muy problemático tampoco ya que la sanción correspondiente es como quitarle un pelo a un gato para una corporación tan grande.
} 
múltiples, apoyos para el cine y en todo caso a la promoción de talento mexicano, lo cual permite en todo caso cumplir con la participación requerida por ley para que una película se considere mexicana. Por tanto, y tomando en consideración tanto el porcentaje de películas norteamericanas exhibidas en México durante 2005, como el porcentaje de coproducciones norteamericanas, es factible observar que 9 de cada 10 películas exhibidas en México aparecen vinculadas de una u otra manera con la industria cinematográfica norteamericana.

Ahora bien, comparativamente con el año 2004 es factible observar que si bien el número de películas norteamericanas bajó apenas en 3 puntos en el año 2005, las películas norteamericanas por coproducción subieron en cinco puntos $^{24}$. Lo anterior indica, un impulso hacia la participación de talentos mexicanos en la producción cinematográfica internacional, pero no necesariamente garantiza la producción propia, el incremento a la creatividad nacional o la difusión de contenidos mexicanos. Así, podemos decir que, en términos generales la tendencia hacia la baja en la participación cinematográfica nacional y el alza en la presencia del cine norteamericano en las carteleras, se mantiene.

No obstante, como los mexicanos nos distinguimos por nuestra creatividad, una de las formas en las que hemos afectado directamente los intereses de las empresas trasnacionales productoras de películas y los de las grandes empresas de exhibición en México, es a través de la piratería. La producción de obras propias ha disminuido, pero ha aumentado el consumo de películas cinematográficas a través de canales informales ${ }^{25}$.

A pesar de la campaña propagandística en contra de la piratería, es común que las personas consigan la película de moda en el mercado negro. El fenómeno está impactando el negocio de las salas de exhibición, al punto que los grandes productores y los conglomerados cinematográficos están buscando desarrollar otras opciones de negocio ${ }^{26}$.

${ }^{24}$ José Carlos Lozano Rendón y Francisco Martínez (2006). Reporte del audiovisual en México: cine/2005. Datos proporcionados electrónicamente por el Centro de Investigación en Información y Comunicación del Tecnológico de Monterrey, Campus Monterrey.

${ }^{25}$ En opinión del director de cine Felipe Cazals, una vez que una película llega a la calle de forma pirata está muerta. Si se puede conseguir en la calle por $\$ 25.00$, con eso ya no se puede competir. Su esperanza es que en los próximos sexenios en México el cine mexicano esté integrado en el presupuesto nacional dentro de un apartado especial. Datos tomados de: Jorge Luna (2005). "Felipe Cazals. Conferencia de prensa" Moovies on line. com Disponible en: http://www.mooviesonline.com/weblog/index.php?p=121

${ }^{26}$ Algunas opciones incluyen, por ejemplo, regalar juegos interactivos, entrevistas especiales, 
A últimas fechas, representantes de la Cámara Nacional de la Industria Cinematográfica y del Videograma están hablando de proponer nuevas modificaciones al esquema reglamentario de esta actividad económica a fin de frenar la piratería ${ }^{27}$ que se lleva a cabo al interior de las propias salas cinematográficas y que atenta directamente en contra de la Ley Federal de Derechos de Autor ${ }^{28}$. Por otra parte, la propia Cámara de la Industria Cinematográfica y del Videograma (CANACINE), denuncia que existe otro tipo de "piratería legal" que consiste en la venta no autorizada de películas en formato de DVD que en ocasiones realizan algunas tiendas, ya que no están cumpliendo con las disposiciones que marca la ley en términos de la autorización y clasificación de material que debe llevar a cabo Dirección de Radio Televisión y Cinematografía (RTC), organismo encargado de definir las restricciones de audiencia de los contenidos fílmicos ${ }^{29}$. Esto genera desorden en la distribución de los materiales que se ponen a la

cupones de descuento de otras empresas u otro tipo de productos de valor agregado para que el consumidor compre la película original y no la pirata. Por otra parte, dado que la piratería ha hecho que se reduzca la afluencia a las salas cinematográficas, cadenas como Cinemex y Cinemarx están poniendo otras opciones como parte del negocio tales como cafeterías y otros locales para hacer más atractivo sus complejos.

${ }^{27}$ México es el primer lugar en Latinoamérica en piratería filmada dentro de los cines, publicó el periódico Reforma, citando a su vez las declaraciones de Steve Solot, vicepresidente de operaciones de la Motion Pictures Association para América Latina quien impartió la conferencia "Tendencias internacionales actuales en el sector audiovisual" dentro del marco de la 12 Convención Nacional de la Canacine, llevada a cabo el 1 de julio del 2005 en Mérida, Yucatán. Fuente: Infosel News en: http://0-site.securities.com.millenium.itesm.mx/doc. $\underline{\text { html?pc }=M X \& \text { doc id=80166539\&query }=\text { ley\%3Aindustria\%3Acinematografica } \& h l c=e s}$ La Canitec por ejemplo incluso instruye a sus socios a poner en marcha acciones específicas en contra de la piratería, ver por ejemplo el Manual en Contra de la Piratería de CANITEC en: http://www.canitec.org/c

Según estimaciones de la PGR entre 1998 y 2002 la piratería causó pérdidas en nuestro país por \$2,818 millones. Ver: Mildred Ramo y Wendy Solís (2004). “Estrategias en contra” Soy Entrepreneur.com en: http://www.soyentrepreneur.com/pagina.hts? $\mathrm{N}=14531$

${ }^{28}$ A este respecto ver por ejemplo: Alberto Aguilar (2005). Columna Nombres, Nombres y ...Nombres Reforma 8 de julio de 2005, publicado por Infosel News ISI Emerging Markets Mexico en: http://0-site.securities.com.millenium.itesm.mx/doc.html?pc=MX\&doc_id=8 $1046937 \&$ query=ley\%3Aindustria\%3Acinematografica\&hlc=es

${ }^{29}$ Durante mucho tiempo el cuerpo legislativo aplicable en este caso fue el Reglamento de la Ley Federal de Radio y Televisión y de la Industria Cinematográfica de 1973 al que se hizo referencia previamente. Ver documento en: http:/www.ordenjuridico.gob.mx/Federal/Combo/Reglamentos/R-87.pdf Actualmente está en vigor el Reglamento de la Ley Federal de Cinematografía publicado en el Diario Oficial de la Federación el 29 de marzo del 2001. Ver documento en: http://www.ordenjuridico.gob.mx/Federal/Combo/Reglamentos/R-82.pdf 
venta al público ${ }^{30}$. Otras industrias como la del fonograma, la televisión por cable y la televisión satelital también están lanzando propuestas a fin de combatir la piratería ${ }^{31}$, por lo que muy probablemente estaremos viendo, y muy pronto, alguna otra modificación al marco regulatorio que rige a la industria cinematográfica y del audiovisual en México.

Por otra parte está la cuestión de la exhibición de contenidos cinematográficos norteamericanos a través de la televisión abierta. ¿Cómo contabilizar dichos impactos directamente en los números de la producción nacional y del impulso a la cinematografía mexicana? Si tomamos en cuenta que la escasa difusión cinematográfica que se hace a través de la televisión abierta también está dominada por los contenidos norteamericanos, entonces podremos concluir que la cinematografía nacional sale muy mal librada en el balance general del consumo ${ }^{32}$.

\section{Política DE COMUNICACión y CINEMATOGRAFÍA MEXICANA}

El problema de proponer una política de comunicación para el sector de la cinematografía en México radica en que el fenómeno es muy complejo. ¿Con qué bases puede proponerse una política de comunicación específica? ¿En qué términos podemos argumentar si una determinada política favorece o no, a través de la reglamentación, a actores específicos dentro del campo del audiovisual y más particularmente dentro de la industria cinematográfica?

\footnotetext{
${ }^{30}$ Ver: Zacarías Ramírez Tamayo. "Noticias financieras”. Miami Abril 16 del 2004. Disponible en: http://0-proquest.umi.com.millenium.itesm.mx/pqdlink?index $=20 \& d i d=64256$ 9911\&SrchMode $=1 \&$ sid $=1 \&$ Fmt $=3 \&$ VInst $=$ PROD\&VType=PQD\&RQT $=309 \& V N a m e$ $=$ PQD \&TS=1124392240\&clientId=23693

${ }^{31}$ Esta iniciativa por lo pronto se refiere exclusivamente a nivel local (Ciudad de México) y fue presentada ante la asamblea de representantes del gobierno del Distrito Federal por parte de los sectores industriales arriba mencionados y se refiere exclusivamente al marco normativo relativo al funcionamiento de establecimientos mercantiles y de cultura cívica del Distrito Federal. Fuente: Notimex, Junio 7 de 2005. Disponible en: http://0-site.securities. com.millenium.itesm.mx/doc.html?.pc=MX\&doc_id=77894452\&query=ley\%3Aindustri a\%3Acinematografica\&hlc=es

${ }^{32} \mathrm{El}$ mismo CINCO ha confirmado con sus resultados que las películas norteamericanas ocupan la mayor cantidad del tiempo destinado a la exhibición del cine en las televisoras mexicanas de tipo comercial. La excepción está en la televisión pública, que sigue transmitiendo una mayor cantidad de películas mexicanas. José Carlos Lozano y Francisco Martínez (2006). Reporte del audiovisual en México: cine/2005. Datos proporcionados electrónicamente por el Centro de Investigación en Información y Comunicación del Tecnológico de Monterrey, Campus Monterrey.
}

Una mirada a las pantallas: oferta cinematográfica en México antes y después del TLC $\bullet 233$ 
La tecnología de producción de cine está cambiando al punto de encontrar a la convergencia tecnológica con otras industrias como la de la computación o el video, de manera que la utilización de software y equipos, necesarios para la producción cinematográfica o para su distribución, está ya en convergencia con la de otras industrias relacionadas como la de la computación y la informática. El cine ya no solamente se ve en las salas cinematográficas, sino que también circula a través de la red y se distribuye en DVD's, tanto en mercados formales como informales. Su consumo trasciende las fronteras mucho más allá de lo que hoy pueden reportarnos las carteleras de las salas de exhibición cinematográficas; de manera que nos encontramos ante un fenómeno de creciente complejidad y alcances.

¿Cómo podemos articular, y lo que es más importante, cómo podemos prever que el marco jurídico vigente logre proteger a la industria nacional en un contexto de competencia no solo internacional sino nacional?

Es un hecho, o al menos así nos lo demuestran las evidencias que hemos encontrado, que el fenómeno es múltiple. Como se mencionó al inicio de este trabajo, el problema del consumo cinematográfico parece estar relacionado no solamente con la oferta, el precio ${ }^{33}$ o las condiciones de exhibición de las películas, sino también con los convenios o los compromisos previos de los exhibidores e incluso con la oferta de quienes ofrecen productos piratas.

En muchos sentidos el fenómeno puede ser semejante al problema de la gallina y el huevo en el sentido de que los consumidores cinematográficos prefieren aquello que se les ofrece, simplemente porque es lo que mayormente se difunde o está más al alcance.

La cuestión de proponer una política cultural y de comunicación de la cual se deriven leyes o reglamentos que ordenen la actividad de una determinada industria, tendría que emerger directamente de buscar un beneficio que otorgue igualdad de oportunidades a quienes deben de beneficiarse del consumo de los bienes culturales en cuestión.

En ese sentido, lo que está a debate es la cuestión del beneficio. ¿Es benéfico preservar la identidad y los valores culturales?, ¿̨o resulta más benéfico exponer al público cinéfilo a las muestras de la cinematografía internacional?

${ }^{33}$ Como vimos anteriormente, en muchos casos el consumo puede estar relacionado con el precio. Los consumidores prefieren películas piratas por ser más baratas que las originales, pero también porque la oferta de películas norteamericanas piratas supera a la oferta de películas piratas de origen nacional. 
Por otro lado, pareciera ser que la oferta cinematográfica de las salas de exhibición mexicanas no es sino un reflejo de la situación internacional. La distribución internacional de cintas cinematográficas se concentra en unas cuantas compañías estadounidenses. Obviamente, las condiciones de negociación que se pueden lograr con un puñado pueden resultar mucho más favorables para garantizar la distribución rápida de los filmes apoyados de todo el soporte mercadológico y publicitario que se requiere para hacer que los espectadores se acerquen a las salas. La justificación de los exhibidores es que ellos simplemente están siguiendo los dictados del mercado, y que el público mexicano que llena las salas busca y pide los productos cinematográficos norteamericanos ${ }^{34}$.

¿Qué podemos proponer entonces, a fin de exigir condiciones de protección a nuestra producción cinematográfica nacional? ¿Cómo podemos garantizar si no el crecimiento, por lo menos la supervivencia de la industria sin impedir que el público mexicano tenga acceso a una oferta de cine variada y de calidad? Esas son algunas de las cuestiones que quedan pendientes para futuros trabajos.

\section{Conclusiones}

Los datos arrojados por este pequeño estudio corroboran la tendencia observada en otros países respecto de la preferencia de filmes estadounidenses en las salas cinematográficas latinoamericanas, (García Canclini, 2004, p. 199 y Rosas Mantecón, 2002 citado por García Canclini). No obstante, en este caso, nuestro estudio apunta a señalar una de las condiciones por las cuales esos altos porcentajes de exhibición de filmes norteamericanos se afianzan en la mente y en las conciencias de los públicos:

Por un lado, los convenios y prácticas comerciales apuntaladas por una gran estructura de comercialización y exhibición que garantiza la difusión de las películas a través de conglomerados de salas cinematográficas con capital extranjero, predominantemente norteamericano.

Por otro lado, la evidencia muestra que la apertura del mercado del audiovisual se vino gestando hábilmente para dejar sentadas las condiciones de la libre

\footnotetext{
${ }^{34}$ Resulta increíble que, siendo que Estados Unidos es el mayor proponente de la liberalización de los mercados sean ellos, quien mayormente protegen a su cinematografía, asignando un rígido favoritismo a sus propias producciones nacionales por sobre la importación de otros filmes. Ver: Néstor García Canclini (2004). Diferentes, desiguales y desconectados. Barcelona: Gedisa, pp. 197 y 198.
} 
entrada de los productos culturales norteamericanos, tal y como lo muestran las modificaciones legislativas hechas a la reglamentación cinematográfica. Adicionalmente, el análisis y los datos adicionales que pudimos obtener nos permiten inferir que el mercado del audiovisual comparte tendencias con otros mercados, tales como el de la música y el software en términos de piratería, por lo que la industria seguramente hará presión sobre las autoridades gubernamentales a fin de modificar la legislación encontrando condiciones cada vez más favorables a los intereses trasnacionales, especialmente norteamericanos, para la explotación del mercado de la cinematografía y el audiovisual.

Por último, nuestro trabajo nos recuerda nuevamente una discusión importante e inconclusa relacionada con la problemática de la gestación de una política cultural y de comunicación viable para México.

El mercado del audiovisual y particularmente del consumo de películas cinematográficas nos ha permitido aquí acercarnos nuevamente al dilema de la gestación de políticas públicas emanadas de los actores nacionales involucrados en una industria así como a la inevitable realidad de que la reglamentación en nuestro país difícilmente emana de una política pública consensuada por los actores involucrados y difícilmente atiende a las necesidades de la sociedad y del bien común; antes bien, la legislación existente sigue respondiendo a los intereses de ciertos grupos y a los compromisos internacionales que nuestro país ha firmado con nuestros más importantes socios comerciales y vecinos.

Bibliografía

García, N. (2004). Diferentes, desiguales y desconectados. Mapas de la interculturalidad. Barcelona: Gedisa

Lozano, J. C. \& Martínez, J. (2005). Reporte del audiovisual en México: cine 2004. Datos proporcionados electrónicamente por el Centro de Investigación en Información y Comunicación del Tecnológico de Monterrey, Campus Monterrey.

Lozano, J. A. \& Martínez, F. (2006). Reporte del audiovisual en México: cine/2005. Datos proporcionados electrónicamente por el Centro de Investigación en Información y Comunicación del Tecnológico de Monterrey, Campus Monterrey.

Luna, J. (2005). Felipe Cazals. Conferencia de prensa, Moovies on line.com. Recuperado en http://www.mooviesonline.com/weblog/index.php?p=121.

Ortiz, J. L. (1989). México en Guerra. México: Editorial Planeta. 
Ramo, M. \& Solís, W. (2004, octubre). Estrategias en contra, Soy Entrepreneur.com. Recuperado de http://www.soyentrepreneur.com/pagina.hts? $\mathrm{N}=14531$.

Rascón, V. H. (2001). Palabras del Presidente de la Sociedad General de Escritores de México, Presentación del reglamento de la Ley Federal de Cinematografía en la Secretaría de Gobernación. CONACULTA/Sala de prensa. Recuperado de http://www.cnca.gob.mx/cnca/nuevo/2001/diarias/mar/300301/leyfcine. html.

SECOFI. (1993). Tratado de Libre Comercio de América del Norte. Recuperado de http://www.economia.gob.mx/work/snci/negociaciones/TLC/pdfs/TLC1. pdf.

SEGOB. (1949). Ley de la Industria Cinematográfica. Diario Oficial de la Federación. 31 de diciembre.

SEGOB. (1973). Reglamento a la Ley de la Radio y la Televisión y la Industria Cinematográfica, Diario Oficial de la Federación. 4 de abril.

SEGOB. (1992). Ley Federal de Cinematografía, Diario Oficial de la Federació.. 23 de diciembre.

SEGOB. (1999). Ley de la Industria Cinematográfica, Diario Oficial de la Federación. 5 de enero.

Solot, S. (2005). Tendencias internacionales actuales en el sector audiovisual, 12 Convención Nacional de la Canacine en Infosel News. Recuperado el 1 de julio, de http://0-site.securities.com.millenium.itesm.mx/doc.html?pc=MX\&doc $\underline{\mathrm{id}=80166539 \& \text { query }=\mathrm{ley} \% 3 \text { Aindustria\%3Acinematografica\&hlc=es. }}$.

Una mirada a las pantallas: oferta cinematográfica en México antes y después del TLC $\bullet 237$ 